\title{
Memorias de la violencia política y formación ético-política de jóvenes y maestros en Colombia
}

\section{//Memories of political violence and ethical- political education of Colombian youth and teachers}

Revista Colombiana de Educación, N. 62 Primer semestre de 2012, Bogotá, Colombia.

\section{//Memórias da violência política e da formação ético-política de jovens e de professores na Colômbia.}

Piedad Ortega Valencia* Martha Cecilia Herrera**
Recibido: 31/10/2011 Evaluado: 28/12/2011- 16/12/201

\begin{abstract}
Doctora en Educación de la Universidad Nacional de Educación a Distancia UNED, magister en Educación y Desarrollo Comunitario de la Universidad Surcolombiana y Administradora Educativa de la Universidad San Buenaventura sede Medellín. Docente-investigadora de la Maestría en Educación y de la Licenciatura en Educación Comunitaria con énfasis en Derechos Humanos de la Universidad Pedagógica Nacional, vinculada al grupo de investigación Educación y Cultura Política. Correo electrónico: piedadortegava@yahoo.es

Doctora en Filosofía e Historia de la Educación de Universidade Estadual de Campinas y magister en Historia de la Universidad Nacional de Colombia. Docente-investigadora del Doctorado y de la Maestría en Educación de la Universidad Pedagógica Nacional, directora del grupo de investigación Educación y Cultura Política. Correo electrónico: malaquita10@ gmail.com
\end{abstract}

\section{Resumen}

Este artículo presenta un avance sobre el proyecto investigativo "Memorias de la violencia política y formación ético-política de jóvenes y maestros", el cual se desarrolla en la ciudad de Bogotá ${ }^{1}$. El problema de investigación se sitúa en la pregunta en torno a: ¿Cómo las memorias acerca de la violencia política configuran subjetividades y se relacionan con la formación ética-política de los jóvenes y maestros en Colombia? Este avance se estructura entonces en relación con la explicitación de su relevancia, el reconocimiento de un contexto sociohistórico, la definición de una ruta metodológica y, finalmente, se da cuenta de algunas tematizaciones inscritas en el proceso de construcción teórica. El marco temporal de la investigación se sitúa en el periodo entre 2000 y $2011^{2}$.

1 Proyecto financiado por el Centro de Investigaciones de la Universidad Pedagógica Nacional (CIUP), vigencia 2001-2012.

2 Es importante destacar que los estudios sobre la violencia en Colombia tienen una carta inaugural a partir de 1987, cuando se crea la "Comisión de Estudios de Violencia". El período nombrado marca la delimitación para el desarrollo de la revisión documental, uno de los procesos del proyecto, el cual se encuentra en ejecución.

\section{Palabras Clave}

Sujetos, memoria, formación ético-política, violencia política. 


\section{Abstract}

This paper gives a synopsis of a research project "Memories of political violence and ethical-political education of youth and teachers," developed in Bogota City. The research problem basically asks the question How memories about political violence set subjectivities and relate to ethical-political education of Colombian youth and teachers? Then this part is structured in connection with explanation of its relevance, the recognition of a socio-historical context, a definition of a methodological route, and finally offers some themes involved in the process of a theoretical framework. The period analyzed of this research is between 2000 and 2011.

\section{Keywords}

Subjects, memory, ethical-political education, political violence.

\section{Resumo}

Este artigo apresenta uma sinopse do projeto de investigação "Memórias da violência política e da formação ético-política de jovens e professore", o que se desenvolve na cidade de Bogotá. O problema de investigação se situa na pergunta sobre: Como as memórias acerca da violência política configuram subjetividades e se relacionam com a formação ético-política dos jovens e professores na Colômbia? Sua estrutura é constituída pela explicação da relevância da investigação, pelo reconhecimento de um contexto sócio-histórico, pela definição de um caminho metodológico e, finalmente, pela apresentação de algumas tematizações inscritas no processo de construção teórica. O marco temporal da investigação se situa no período de 2000 a 2011.

\section{Palavras chave}

Sujeitos, memoria, formação ético-política, violência política. 


\section{Presentación}

A este amargo país de los silencios, de los olvidos y de los miedos

A las Madres de Soacha

Detrás de la ventana

Una mujer llora a sus muertos.

Una mujer llamada soledad.

Ella cubre con sus pechos

las fosas de sangre

regadas en el asfalto.

Una mujer

detrás de la ventana

llora a sus hijos.

Ella cubre con excremento y cal

las tumbas con las que tropiezan los

transeúntes.

Detrás de la ventana

Ella reza una oración,

un poema,

una canción fúnebre.

El proyecto "Memorias de la violencia política y formación éticopolítica de jóvenes y maestros en Colombia"1 $^{\prime \prime}$, tiene como propósito interpretar en la memoria de estos grupos poblacionales los efectos de la violencia política y cómo esta configura sus procesos de subjetividad y de formación ético-política. La perspectiva teórica en la que se inscribe este objeto de estudio es de carácter interdisciplinar, en la cual la sociología, la historia, la ciencia política, la filosofía y la pedagogía se han constituido en los referentes para el trabajo epistemológico, cate-

\footnotetext{
En el proyecto de investigación participan también en calidad de investigadores los profesores Vladimir Olaya y José Gabriel Cristancho. Hacen parte igualmente del grupo los estudiantes que realizan sus estudios de Maestría y Doctorado en Educación de la UPN.
}

gorial y analítico del proceso teórico y metodológico que se agencia.

Se justifica el desarrollo de este proyecto dada la incidencia de las situaciones de violencia política en las sociedades, tanto en el plano macro como microsocial, en América Latina y en Colombia en particular, las cuales conducen a señalar la importancia de llevar a cabo investigaciones que permitan profundizar en torno a la formación de subjetividades $y$ al papel de la memoria, social e individual, como mediadora de las significaciones en torno a dichas situaciones. La memoria, al ser memoria viva, recrea y reelabora las experiencias vividas $y$, en este sentido, ayuda en la configuración de las identidades sociales e individuales, así como de las subjetividades. En este contexto hay dos demandas necesarias de trabajar en torno a las víctimas de la violencia política: la primera, sujetos que hay que dignificar en relación con los procesos de reparación colectiva, en torno al reestablecimiento de los derechos vulnerados y a la reparación de los daños ocasionados a las comunidades; y la segunda demanda, referida a la restitución del derecho a la verdad y a la justicia y la creación de condiciones sociales, políticas y educativas en las diferentes esferas de lo público para su plausibilidad.

De este modo, tratar de comprender mejor cómo opera la memoria social e individual, sobre fenómenos específicos, como es el caso de la violencia política, permitirá esclarecer de mejor manera sus conexiones 
con la formación de los sujetos, así como las distintas estrategias de pedagogía en torno a la memoria que son puestas en acción por las diferentes políticas promovidas tanto por el estado, como por los actores del conflicto y por la sociedad civil en general ${ }^{2}$.

La investigación pretende partir de las diversas narraciones de los sujetos implicados, comprender e interpretar la configuración y la constitución de la memoria individual y la memoria colectiva acerca de la violencia política. Es decir, se intenta reconocer la construcción de la subjetividad política y las formas de socialización de los jóvenes y maestros a partir de sus narraciones y experiencias de reconocimiento. En tal sentido, la investigación es de naturaleza hermenéutica, interpretativa-comprensiva.

Se quiere destacar que es un propósito fundamental en esta investigación formar y consolidar un grupo de jóvenes y maestros investigadores a nivel de maestría y doctorado con soportes teóricos y metodológicos de carácter interdisciplinario para indagar y producir teoría desde este abordaje, al igual que contar con la posibilidad de tener incidencia en contextos y procesos de formación ${ }^{3}$.

2 Se registra en el 2005 la creación de la Comisión Nacional de Reparación y Reconciliación, la cual cuenta con un grupo de trabajo sobre memoria histórica, bajo la coordinación de Gonzalo Sánchez, cuyo propósito es el análisis de la violencia que ha soportado el país desde los inicios del conflicto contemporáneo hasta hoy, sin prejuicio de la definición o no de un período histórico para el desarrollo de sus políticas de reparación. (http:// www.cnrr.org.co/memoria_historica.htm).

3 Es importante anotar que a la fecha el colectivo de estudiantes que integran el grupo de investigación en Educación y Cultura Política desde el seminario proyectos de investigación y en calidad de tesistas, se encuentran desarrollando sus proyectos desde los siguientes objetos de indagación: Clara Castro: Voces de jóvenes víctimas de la Unión Patriótica: El lugar de la memoria en la constitución de sujetos éticos-políticos; Angie P. Rojas: Memorias de la violencia y construcción de identidades y narrativas juveniles en Colombia. Un estudio a partir de relatos cinematográficos; Luz Dary González: El performance como soporte de la memoria en jóvenes afectados por la violencia política; Pablo Vargas: Memorias de la violencia política en los sujetos escolares y sus implicaciones en la formación ética: Continuidades y rupturas; Javier U. Flórez: Horizontes ético-políticos de jóvenes afectados por la violencia política en la ciudad de Bogotá; Rocío Hernández: Memorias juveniles: concepciones ético-políticas de la violencia y su relación con la escuela en jóvenes de "parches" y desplazados; Edwin Ordóñez: Memoria y narrativa en los procesos de formación ético-políticos de jóvenes víctimas de la violencia; Andrés Avella: Memorias del desplazamiento y construcción de sujeto en el marco del proyecto agroindustrial en Colombia; Jertiza Merchán: Las voces de los sobrevivientes de genocidio político en Colombia: diseño de un museo virtual; José G. Cristancho: Memorias sobre grupos políticos de oposición y subjetivación política en el cine argentino y colombiano; Miller Pérez: Memoria de la violencia política en la narrativa de jóvenes escolares del sur del departamento de Casanare; Felipe Patiño: Narrativas musicales, jóvenes y violencia política en Colombia. Cuando la memoria se hace música; Mariana Simbaqueba: Memoria de la piel: Prácticas constituyentes de los cuerpos juveniles; Marcela González: Juventud y violencia política: Emprendedores de memoria en el caso de los "Falsos Positivos"; Lina Ramírez: Mujer y violencia política: Emprendimientos de memoria de mujeres en condición de desplazamiento forzado; Boris Rocha: Lo público es como un campo de combate. Metáforas de lo público en las narraciones de maestros sindicalizados. 


\section{Contexto y problematización de la investigación}

Se asume el contexto como un referente macro que habla de sentidos, situaciones y condiciones en el que se sitúa este objeto de estudio. Lógicas en las que se estructuran y constituyen las realidades sociales. Tendencias que dan sentido y permiten ubicar e interpretar el quehacer social de grupos poblacionales. Desde esta orientación el contexto colombiano se caracteriza por el mantenimiento de una prolongada situación de violencia política y conflicto armado interno, no reconocida por el Estado colombiano, que ha dejado un sinnúmero de víctimas de crímenes como el desplazamiento forzado ${ }^{4}$, asesinatos selectivos, desapariciones forzadas, ejecucione

4 Se considera el desplazamiento forzado no como un fenómeno sino como un crimen de lesa humanidad frente al cual se evidencia una responsabilidad por parte del Estado colombiano. La magnitud del desplazamiento forzado en el país y la cifra de 4 millones de personas víctimas de este crimen, plantea la necesidad de develar la implementación de una estrategia de despojo de los territorios. Planteamiento retomado de Castro, C. (2010). Formulación de su proyecto de investigación "Voces de jóvenes víctimas de la Unión Patriótica: El lugar de la memoria en la constitución de sujetos éticos y políticos". extrajudiciales ${ }^{5}$ y amenazas ${ }^{6}$, entre otros crímenes que en su gran mayoría se mantienen en la impunidad. Esta realidad se hace más compleja con la implementación de la política de seguridad democrática ${ }^{7}$, la visibilización internacional por parte del gobierno colombiano de la "desmovilización" de los grupos paramilitares, la ficticia entrada a una era de postconflicto y con los ataques de la insurgencia a los movimientos indígenas, campesinos y afrodescendientes.

En el marco de este proyecto, la violencia política es entendida, acogiendo la comprensión del Centro de Investigación y Educación Popular (CINEP) "como aquella ejercida como medio de lucha político-social, ya sea con el fin de mantener, modificar, sustituir o destruir un modelo de Estado o de sociedad, o también con el fin de destruir o reprimir a un grupo

5 O mal llamados "Falsos Positivos". Las cifras del 2009 le otorgan un lugar relevante a las ejecuciones extrajudiciales, las amenazas colectivas y los crímenes por intolerancia social, las cuales tuvieron un lugar protagónico como hechos atroces. Al respecto, el Banco de Datos de CINEP plantea que en el acumulado de falsos positivos durante el período 2001-2009 se registran 465 casos y 940 víctimas que en su mayoría habían sido clasificados como acciones en combate. CINEP. (2009). Informe especial. Primer Semestre de 2009: De los 'Falsos Positivos' a la intolerancia social y las amenazas colectivas. Bogotá.

6 Señalamientos, amenazas y atropellos a los jóvenes pertenecientes a organizaciones políticas Una de las modalidades más utilizadas ha sido la circulación de panfletos y la realización de campañas de amenazas colectivas en ciudades como Cali, Medellín y Bogotá

7 Expedida y sostenida durante el gobierno de Álvaro Uribe en sus dos periodos (2002-2010). 
humano con identidad dentro de la sociedad por su afinidad social, política, gremial, étnica, racial, religiosa, cultural o ideológica, esté o no organizado" (2008, p. 5).

La postura antes enunciada significa, también, comprender que los sujetos habitados por procesos y dinámicas de violencia política están insertos en un repertorio de discursos, prácticas y significaciones que coadyuvan a formar estructuras ético-políticas, es decir, unos modos de comprender lo humano y las formas del tejido social. Ahora bien, uno de los sujetos que ha emergido en la escena social, cultural, política y por supuesto en los contextos de violencia durante las dos últimas décadas en el país son los jóvenes. Estos han sido visibilizados tanto como sujetos de protección, de derechos, en estado de riesgo, en condiciones de vulnerabilidad y sujetos de prevención, así como víctimas y victimarios de los diversos conflictos. Este grupo poblacional es quien vive de una forma más cruel la crisis estructural ${ }^{8}$, las violencias y conflictos de los últimos años. Las narrativas que hablan de esta crisis evidencian unas maneras de ser, de pensar y de actuar ante la violencia política, algunas de las cuales han sido visibilizadas a través de medios de comunicación de amplia difusión o de investigaciones académicas de carácter histórico, político y antropológico ${ }^{9}$, o de diversos registros artísticos y literarios $^{10}$.

Transversal a los jóvenes como sujetos de la investigación ${ }^{11}$ y a la manera como les afecta la problemática de estudio, emergen también los maestros ${ }^{12}$ como actores importantes. Estos se

8 Crisis que es sostenida por condiciones y situaciones de desigualdad y exclusión. Una exclusión que los expulsa de las políticas, de los escenarios y de la posibilidad de contar con trayectorias vinculares.

9 Algunos trabajos a destacar en este orden son: Laverde, Daza y Zuleta M. (ed.) (2004); Rodríguez (2009); Vélez (2003); Castillejo (2000).

10 La literatura y el cine "plasman el binomio jóvenes-violencia a través de textos como No nacimos Pa semilla (Alonso Salazar), La virgen de los sicarios (Cesar Vallejo), Rosario Tijeras (Jorge Franco) y Rodrigo D, No futuro (Víctor Gaviria), mientras que la televisión emite gran cantidad de seriados en donde los principales protagonistas de las diferentes formas de violencia social son los jóvenes". Avances tesis de Alvaro Chaustre. Doctorado en Educación, UPN.

11 Sobre la especificidad de los jóvenes con quienes se está trabajando los procesos de "generación de información", se definió como criterio metodológico no trabajar con la tipología de jóvenes víctimas, victimarios o testigos, sino con "jóvenes afectados por la violencia política". En esa medida se opta por dos configuraciones: i) jóvenes de los grados décimo y undécimo de instituciones educativas ubicadas en los sectores populares receptoras de poblaciones en condiciones de desplazamiento (configuración etárea entre 17 y 18 años) y, ii) jóvenes que participan en espacios y procesos de organización y formación política, (configuración etárea entre 18 y 22 años).

12 Importante la referencia al trabajo de investigación inscrito en el desarrollo de su tesis doctoral "Ambiente educativo de las escuelas en zonas de conflicto armado" del profesor Mauricio Lizarralde de la Universidad Distrital. Bogotá. 
configuran como mediadores de los conflictos, formadores políticos, constructores de convivencia, facilitadores de paz, pero a su vez se les responsabiliza, en muchos casos, de la escalada violenta, como consecuencia de insuficientes procesos educativos que no tienen en cuenta la formación ético-política que estos contextos necesitan ${ }^{13}$. Así pues, el maestro vive en medio de complejos contextos violentos en los que su existencia acumula la experiencia misma de la violencia, su actuación, su responsabilidad como formador de sujetos y su práctica misma le reclaman una postura ante estas situaciones y problemáticas y el agenciamiento de horizontes de futuro en torno a ellas.

A pesar de la complejidad de este contexto y en medio de condiciones de ausencia de garantías para actores vinculados con el agenciamiento de iniciativas de lucha contra la impunidad, en Colombia se cuenta con estrategias de exigencia y reivindicación de derechos por parte de organizaciones indígenas, afrodescendientes, campesinas, defensoras de derechos humanos y de víctimas. Desde estas mismas propuestas, se vienen adelantando en el país iniciativas de recuperación y fortalecimiento de los procesos de resistencia, defensa del territorio e iniciativas para mantener viva la

13 Contextos marcados por una alta conflictividad que tiene múltiples expresiones. Las escuelas de sectores populares son las mayores receptoras de población en condición de desplazamiento memoria como los proyectos: "Colombia Nunca Más", "Galerías de la Memoria", las estrategias del "Movimiento Nacional de Víctimas de Crímenes de Estado -MOVICE-"; el proyecto "Memoria viva de las víctimas de la Unión Patriótica", entre otros.

Estas iniciativas tienen el reto de acercar la sociedad a las víctimas y sobretodo superar la invisibilización con la que se han encontrado las víctimas de violencia política en el escenario público, así como el agenciamiento de políticas tendientes a que se lleven a cabo en el plano de la memoria colectiva e individual formas críticas de releer el pasado, con miras a llevar a cabo reflexiones sobre los fenómenos de violencia política y construir horizontes de futuro que posibiliten el agenciamiento de vínculos en condiciones de justicia, dignidad y solidaridad.

Es por ello que en Colombia hablar de víctimas implica remitirnos a un contexto caracterizado por violaciones masivas y sistemáticas de los derechos humanos, las cuales se han visto agravadas por el mantenimiento de condiciones de impunidad ante los crímenes cometidos. De esta manera, estas situaciones nos exigen ubicarnos en un contexto en donde sigue presente la amenaza, el silenciamiento, la estigmatización y la fragmentación social, y nos invita a hacer un ejercicio analítico en dos ámbitos de reflexión: el primero sobre los procesos de resignificación 
y dotación de sentido de los hechos por parte de las víctimas y la sociedad en su conjunto, y el segundo en relación a las condiciones socio-políticas y culturales que posibilitan o limitan la emergencia de la memoria en los procesos de construcciones éticas-políticas, en el marco del desarrollo del presente proyecto de investigación.

El renacer de los discursos sobre la memoria comienza a obtener visibilidad en la década del 60 del siglo pasado, como resultado de la descolonización y de los movimientos sociales que buscaban historiografías alternativas para legitimar su accionar. Estos discursos cobraron mayor vigor en Europa y en Estados Unidos a comienzos de los años 80 con motivo de las valoraciones que se hicieron en torno al Holocausto (Huyssen, 2007; Cuesta, 2008). Dentro de este escenario, en el contexto latinoamericano las reflexiones en torno a la memoria han estado motivadas por fenómenos referentes a las dictaduras y sus procesos de transición hacia regímenes democráticos, como es el caso de países como Argentina, Uruguay, Chile, Paraguay, Perú, así como fenómenos de polarización política como en Colombia, Venezuela y Bolivia, entre otros, han estado acompañados de un movimiento por incorporar los temas del pasado en la memoria social. Las luchas políticas dadas en el contexto postdictatorial en los países del Cono Sur, referentes al ajuste de cuentas con el pasado, dieron énfasis inicialmente a categorías como la verdad, la justicia o la búsqueda de sentido del pasado doloroso, habiendo pasado en las décadas recientes a dar prioridad al problema de la memoria en el marco de los derechos humanos, como lo menciona Jelin (2003). Por ello para Cabrera una de las alternativas es:

Trabajar con la memoria en la construcción de un relato histórico que rompa la percepción de circularidad, que muestre las rupturas y continuidades de la violencia, que exponga el modelo de formación de memoria imperante, y finalmente, que al hacer justicia a las víctimas o imputar responsabilidades logre escapar de los modelos de compensación que contribuyen a la lógica de mercantilización de la violencia (2006, p. 52).

Se asume que la memoria es un elemento simbólico que dignifica a las víctimas y promulga en el conjunto de la sociedad el reconocimiento de su pasado, posibilitando la no repetición de 
los hechos que vulneraron los derechos fundamentales de la población. Sin embargo, el contexto colombiano continúa generando varias preguntas sobre los contenidos, propósitos y condiciones de los procesos de reconstrucción de la memoria: ¿Cómo es posible que una persona sobreviviente elabore, resignifique y haga memoria, cuando para el conjunto de la sociedad muchas de las violaciones ni siquiera ocurrieron? ¿Cómo poner las narraciones de las víctimas en espacios públicos cuando no hay garantías de seguridad y los crímenes continúan? ¿Cómo hablar de memoria cuando el conjunto de la sociedad olvida fácilmente lo que ocurre en el país y naturaliza la violencia como una forma más de relación? Atender a la significación de estas preguntas nos remite a develar las siguientes problematizaciones, las cuales han sido asumidas en la dinámica misma de la investigación: I) la negación de reconocimiento que prevalece en medio de la continuidad de las violaciones a los derechos fundamentales, II) los procesos agenciados por las víctimas desde el reconocimiento de sus capacidades, asumiéndose como sujetos políticos y de derecho, III) el valor ejemplarizante de la historia, no como un asunto exclusivo de las víctimas, sino como algo que compete a la sociedad en su conjunto, pues lo que se ha visto lesionado es en sí el concepto de humanidad, IV) la desvergüenza existente en las estructuras subjetivas y sociales que tienen como efecto la desresponsabilización en los actos de violencia política en sus efectos de degradación social y política, V) el agenciamiento de proyectos de formación ético-políticos que no hacen reconocimiento del contexto de la violencia política y VI) las disposiciones, posiciones y actuaciones amnésicas de buena parte de la sociedad colombiana.

El propósito de trabajar en torno a estas problematizaciones ha estado orientado por los siguientes objetivos: I) identificar y comprender en las narraciones de los jóvenes y maestros las huellas de situaciones de violencia política, II) caracterizar diferentes soportes que vehiculizan la memoria individual y la memoria colectiva en torno a fenómenos de violencia política, III) reconocer el papel de la memoria en la constitución de identidades y su incidencia en la configuración de subjetividades políticas, IV) develar en las actuaciones de los jóvenes y de los maestros sus comprensiones éticospolíticas sobre la violencia y, V) formular un programa de formación ético-política que posibilite el agenciamiento de procesos formativos desde una pedagogía de la alteridad y de la memoria.

\section{Ruta Metodológica}

Si asumimos, con Taylor y Bogdan, que una metodología designa "el modo en que enfocamos los problemas y la manera en que buscamos sus respuestas, su definición no puede limitarse a términos instrumentales, 
exige hacer explícito cómo se entiende el fenómeno por investigar, el enfoque asumido para abordarlo y las fases y decisiones del diseño metodológico" $(1992$, p.5).

Al respecto, esta investigación se ubica en el paradigma de la investigación cualitativa, desde un enfoque hermenéutico con la intención de explorar y leer contextos, textos y acciones de los sujetos implicados en este proceso ${ }^{14}$. De acuerdo con Merleau-Ponty (1975), la hermenéutica es apropiada para la articulación con sentido de perspectivas teóricas y metodológicas, para objetivar lo social y reconocer un sujeto socio-histórico con potencialidades para representar, para imaginar, para hacer y hacerse. La hermenéutica permite acercarse a vidas ajenas y extrañas que conviven con la experiencia propia, pues la autocomprensión y la comprensión de otras vidas no son inseparables. Por ello todo proceso investigativo implica una relación de alteridad y responsabilidad, una relación con el otro, donde el extraño se convierte en cómplice desde sus propias memorias, corporeidades y producción de narrativas.

Se trata, de acuerdo a esta orientación, de asumir un rol de intérprete en los acercamientos e interacciones con los sujetos y sus dinámicas, tratando de hacer conscientes las dimensiones histórica, cultural, política y pedagógica configurativas de estas. Por lo tanto, esta investigación se orienta hacia la comprensión de la realidad como resultado de un proceso histórico de construcción a partir de las lógicas de los sujetos, reconociendo y recuperando sus diferencias y particularidades.

Uno de los aspectos más significativos de este paradigma cualitativo es el de no permitir la mirada del sujeto desde una cifra estadística, desprovista de contexto, exento de subjetividad y de sus posibilidades para generar un diálogo de saberes como el que plantea Paulo Freire, donde se construyen nuevos conocimientos a partir de procesos colectivos. Taylor y Bogdan mencionan tres condiciones necesarias para la producción de conocimientos, las cuales hemos asumido en esta ruta: I) recuperación de la subjetividad como espacio de construcción de la vida humana, II) reivindicación de la vida cotidiana como escenario básico para comprender la realidad sociocultural y III) la intersubjetividad como vehículo para acceder al conocimiento.

14 Algunos de estos procesos metodológicos han sido: I) contextualización temática, la cual se ha trabajado desde la técnica de la revisión documental; II) procesos de sistematización, análisis e interpretación, que ha significado el desarrollo del trabajo de campo, la definición de sujetos, escenarios, fuentes y prácticas para la fase de generación de información; y finalmente III) la construcción teórica, de la cual exponemos algunas de las tematizaciones que se han elaborado. 
Partiendo de los aportes de Blair, se reconoce la memoria "como un proceso colectivo y social en la medida en que está mediada por el lenguaje y en que es, en tanto miembro de un grupo, que un colectivo recuerda" (2002, p. 26). De ahí que la memoria

Acude al relato para dar una posición, una historia y una identidad al sujeto, pero necesariamente en relación con los otros (...). De esta manera, la narración emerge a través de relatos elaborados no a partir de una producción exacta, escrupulosa y lineal de la sucesión de acontecimientos, sino que se produce secuencialmente estableciendo relaciones, aportando detalles, introduciendo conocimientos socialmente compartidos, pudiéndose desplazar a través del pasado, del presente $y$ del futuro, aprovechando la virtualidad que la narración tiene de poder reconfigurar el tiempo (p. 25).

La narración da cuenta de un quién que narra y a través del lenguaje comprende la experiencia del tiempo y del mundo, es decir, en palabras de Cruz (2000), organiza su experiencia humana en el tiempo. Por lo tanto, las narraciones son sociales en la medida en que quien narra lo hace para que otros lo escuchen y con su relato se hace responsable frente a lo que dice.

Sin embargo, pensar en la narración como una estrategia (Arfuch, 2008) para devolverle la voz a quienes no la tienen en un contexto de temor, silenciamiento y amenaza, nos lleva más allá del análisis de quién relata y nos invita entonces a pensar en las condiciones sociales y políticas para poner la narración en espacios públicos, es decir, como un dispositivo de argumentación política (Ricoeur, 2006).

Es por ello que la exigencia de investigar e investigarse implica el reconocimiento de una ética que regula la manera como el investigador realiza sus proyectos. La investigación implica el reconocimiento de principios éticos, una apuesta política, una puesta en escena estética y un proceso cognitivo, donde se pone de manifiesto la responsabilidad del investigador en sus diálogos y en sus resistencias con un "otro" que es radicalmente diferente. El sujeto es complejo, sus relaciones están estrechamente conectadas con sus historias, experiencias, sensibilidades, corporeidades, prácticas y por sus expectativas con el mundo, de ahí que las construcciones que genera con los otros son diversas, conflictivas, afectivas y por supuesto demandantes, lo que le exige una negociación permanente de sentidos y apuestas de vida. 


\section{Proceso de construcción teórica's}

Para el desarrollo de los objetivos anteriormente expuestos, se ha definido una estructura categorial ${ }^{16}$ que es el soporte para la construcción teórica de la investigación. Estructura que ha permitido orientar epistemológicamente la revisión documental, elaborar algunos ejes de agrupación temática e identificar recursos analíticos para los procesos de diseño, generación y análisis de la información. De acuerdo a esta orientación, el grupo de investigación ha definido una tematización nucleadora nombrada como "Memorias sobre la violencia política y formación de subjetividades", y en relación con esta viene construyendo tematizaciones específicas alrededor de "políticas de la memoria, narración y formaciones ético-políticas", "formación de subjetividades, memoria y narrativas audiovisuales" $\mathrm{y}$ "pedagogías de la alteridad en procesos de formación ético-política". A continuación se presentan algunas de las tematizaciones que dan cuenta de este proceso.

\section{Sujetos y constitución de subjetividades como parte de la dinámica cultural}

Uno de los temas/problemas que ha cobrado importancia en las discusiones dadas en el campo del pensamiento social, desde finales del siglo XX, ha sido el del sujeto y la subjetividad como parte de las tentativas de comprensión de las sociedades y de las culturas contemporáneas (Laverde, M.C., Daza G., Zuleta M., 2004). Al respecto argumenta Cruz que:

Ese ámbito que hoy denominamos subjetividad representa algo así como el espacio en el que los discursos vierten sus determinaciones para configurar esa categoría más amplia que denominamos sujeto. Con otros términos: nuestro supuesto es el de que, cuando los sociólogos hablan de individuo y piensan sus rasgos característicos,

15 Es un proceso que busca dar cuenta de los referentes teóricos que orientan el abordaje del objeto de estudio. Nos remite a teorías configurativas del asunto que se investiga, donde se toman opciones disciplinarias para la estructuración temática. Es un proceso donde se ponen de manifiesto las opciones experienciales, ideológicas, disciplinares y teóricas del grupo de investigación.

16 Según Galeano, E. (2007), la investigación cualitativa estructura su trabajo en torno a categorías. Estas son constructos teórico-metodológicos que apoyan conceptual y metodológicamente el trabajo investigativo, aportando a la clasificación, lectura y recuperación analítica de la producción existente sobre determinado objeto. 
los éticos a lo largo de su reflexión moderna y contemporánea, se sirven de la noción de identidad moral, los antropólogos reflexionan sobre las condiciones necesarias para reconocerle a alguien la condición de persona, determinados filósofos contemporáneos se refieren a la conciencia, o cuando los sicoanalistas tematizan el yo, están prefigurando, anunciando las determinaciones del concepto. Eso obviamente no significa que hoy dispongamos de una imagen unívoca o coherente del sujeto: significa tan sólo que las diversas determinaciones con las que lo entendemos tiene ese variado origen discursivo (1996, p. 15-16).

Al pretender dar luz respecto a las formas de constitución de los sujetos y de las subjetividades, estos acercamientos han posibilitado restituir el papel de los individuos en el agenciamiento de las instituciones sociales, al cuestionarse tanto abordajes en los que la realidad social estaba conformada por estructuras ausentes de seres humanos y a cuyas lógicas estos debían someterse (característicos de la sociología de corte durkheiniano y/o parsoniano), como acercamientos hermenéuticos en los cuales el individuo era amo y señor de sus significaciones y decisiones en el campo de la vida y la acción social (Reguillo, 2000).

Tratando de resolver estas dificultades, autores como Elías (1997), Chartier (1992), Guidens (2003), Scott (2001), Garrieu y Lacroix (1997), señalan la permanente tensión entre lo social y lo individual para el análisis de la realidad social, así como la importancia de su abordaje en cuanto categorías que forman parte de una unidad irreductible. En esta dirección se resalta la centralidad de la experiencia para entender las prácticas sociales y las formas de constitución de la subjetividad, destacándose el papel de la memoria y de la narración para su articulación y procesamiento (Scott, 2001; Rossi, 2003). Es a partir de esta última perspectiva que esta investigación sitúa algunos de sus presupuestos de carácter epistemológico para la comprensión de algunas de las categorías que se constituyen en ejes nucleares del objeto de estudio en lo referente a los sujetos y su lugar en la dinámica social, a la constitución de subjetividades y los procesos de subjetivación, señalando su articulación con categorías como experiencia, prácticas, memoria, alteridad y narración, entre otras.

El estudio de problemas y de categorías relacionadas con el sujeto, los procesos de subjetivación y la constitución de subjetividades, requiere tener como referente que estas no son categorías sustantivas ni hacen parte de procesos que se 
dan en el vacío, sino que tienen como marcos referenciales las sociedades y las culturas en las cuales están ancladas (León y Zemelman, 1997; Ricoeur, 2001). La preocupación por los seres humanos, sus características, así como el lugar que ocupan en las elaboraciones conceptuales en torno a la sociedad y a la cultura, ha conducido a búsquedas relacionales en distintas tradiciones del pensamiento social, aunque se le hubiese abordado desde diferentes enfoques y distintas denominaciones.

Los miembros de una sociedad experimentan procesos de individuación a través de los cuales se configuran como sujetos específicos, en un movimiento pendular incesante por medio del cual se apropian, recrean y reelaboran, a través de prácticas sociales y de su interacción con los otros sujetos, las significaciones culturales que les permiten comprender y procesar sus experiencias, darle sentido a sus actuaciones y delimitar los términos de sus interacciones sociales. De esta manera, sus subjetividades van siendo moduladas a la luz de complejos dispositivos de subjetivación (Rose, 2001), por medio de los cuales los individuos se constituyen en determinado tipo de sujetos en contextos históricos y culturales específicos. Lo anterior no quiere decir, en ningún momento, que se llega a ser sujeto de un modo definitivo; en verdad el término que mejor expresa esta idea es devenir, en tanto alude a la constitución del sujeto como un proceso permanente, dinámico e inacabado, en permanente interacción con la cultura.

Para señalar las diferentes formas como se modulan las subjetividades, Alfredo de la Garza se refiere a los campos de la subjetividad como espacios que "contienen elementos acumulados para dar sentido socialmente, no a través de la identificación de códigos que reducirían la subjetividad a la cultura, sino como proceso que se incorpora a los códigos acumulados creando configuraciones subjetivas para la situación concreta". Así, el autor delimita campos como:

El del conocimiento, en tanto cognición, y que incluye la información, su jerarquización; el de las normas y valores a la manera de las teorías tradicionales de la cultura; el del sentido estético; el del sentimiento como fenómeno social; y el del razonamiento cotidiano. El discurso podría sintetizar lo antes dicho, expresarlo como producto subjetivo, pero toda síntesis es simplificación y con ello pérdida de significado (De La Garza, 2001, p. 14). 
Experiencia y prácticas como constitución de subjetividades

En la comprensión de las subjetividades cobran interés la categoría de experiencia para estudiar los procesos y mecanismos a través de los cuales se constituyen los sujetos, las identidades/alteridades sociales e individuales. Para Foucault, la estructuración de la experiencia del ser humano moderno puede ser rastreada alrededor de tres ejes: "la formación de los saberes que a ella se refieren, los sistemas de poder que regulan su práctica y las formas según las cuales los individuos pueden y deben reconocerse como sujetos". Por eso este autor entiende por experiencia "la correlación, dentro de una cultura, entre campos de saber, tipos de normatividad y formas de subjetividad" (1984, p. 8). Así, es la experiencia la que modula la constitución del sujeto, ya que, desde esta perspectiva, "no son los individuos los que tienen la experiencia, sino los sujetos los que son constituidos por medio de la experiencia (...) Pensar de esta manera la experiencia es darle historicidad, así como dar historicidad a las identidades que produce" (Scott, 2001, p. 49-50).

De este modo la experiencia no se entiende como algo que puede ser leído por el sujeto de manera transparente, sino que requiere de un proceso de interpretación, digamos que de una producción reflexiva de sus propias prácticas. En este proceso de construcción de subjetividad el lenguaje es un aspecto determinante, en la medida en que a través de él nos constituimos como seres humanos, capaces de incorporar y adecuar las particularidades culturales del entorno social en cual hemos nacido o nos encontramos. Así, en el proceso de individuación, de constituirse sujeto, el recién nacido, o el recién llegado, incorpora la cultura en la misma medida que incorpora el lenguaje que la nombra. $\mathrm{Al}$ ser el lenguaje un código cultural compartido y constituirse como posibilidad de referirse a la experiencia, interpretar las propias prácticas y las de los demás, podemos decir que la experiencia es tanto colectiva como individual: "La experiencia es la historia de un sujeto. El lenguaje es el sitio donde se representa la historia. La explicación histórica no puede, por lo tanto, separarlos" (Scott, p. 65-66).

En este marco de comprensión, experiencia y práctica deben ser entendidas como relacionales, ya que los individuos y las sociedades están atravesados por un sinnúmero de prácticas a través de las cuales se constituye la experiencia. En términos de Foucault "son las prácticas concebidas como modos de actuar (prácticas de poder) y de pensar (prácticas de saber) las que ofrecen la llave de la inteligibilidad para comprender la constitución del sujeto" (Muñoz, 2007, p. 86). Es dentro de las instituciones que se instauran una serie de reglas, 
normas y disposiciones que interpelan a los individuos y ponen en marcha procesos de socialización y subjetivación que inciden, a través de diversos dispositivos, en la constitución de subjetividades. Desde este punto de vista, "el sujeto se construye desde la exterioridad de las prácticas discursivas pero a la vez estas prácticas le impelen a reflexionar sobre su accionar y sobre su relación consigo mismo" (Vanegas, 2002, p. 140).

\section{Experiencia, memoria y subjetividades}

Si buena parte de lo que somos como género humano tiene relación con la capacidad de acumular los conocimientos y los aprendizajes a lo largo de siglos y de complejos procesos de intercambio generacional, la memoria le ha permitido a la humanidad la conservación, transmisión y recreación del bagaje social y cultural acumulado en el devenir histórico. En este sentido, es pertinente señalar su papel como articuladora de los múltiples sentidos de la experiencia y de las prácticas sociales, así como de las percepciones de temporalidad implícitas en dichos procesos y del papel jugado por la narrativa (Ricoeur, 2002, p. 318).

Las prácticas de recuerdo y olvido se constituyen en mecanismos culturales selectivos que permiten a las sociedades y a los individuos dar sentido y continuidad a su existencia, pudiendo situar dentro de un mismo entramado las experiencias pasadas con las actuales, al tiempo que tener una proyección, una expectativa que avizore el horizonte futuro. Jelin, afirma que:

La experiencia es vivida subjetivamente y es culturalmente compartida y compartible. Es la agencia humana la que activa el pasado, corporeizado en los contenidos culturales (discursos en un sentido amplio). La memoria, entonces, se produce en tanto hay sujetos que comparten una cultura, en tanto hay agentes sociales que intentan 'materializar' esos sentidos del pasado en diversos productos culturales que son concebidos, o que se convierten en, vehículos de la memoria, tales como libros, museos, monumentos, películas o libros de historia. También se manifiesta en actuaciones y expresiones que, antes que re-presentar el pasado, lo incorporan performativamente (2002, p. 37).

La memoria permite a los individuos y a los grupos dar sentido y organizar sus concepciones y prácticas sociales a través de las múltiples narraciones que llevan a cabo en torno a sí mismos, 
a los otros y a las experiencias sociales en las cuales están inmersos. Según Ricoeur: "en el plano más profundo, el de las mediaciones simbólicas de la acción, la memoria es incorporada a la constitución de la identidad a través de la función narrativa" (2002, p. 115). Para el historiador y sociólogo inglés Connerton, interesado en el estudio de la memoria colectiva y el papel de lo performativo, "la narrativa de una vida es parte de un conjunto de narrativas interconectadas, está embebida en la historia de los grupos de los cuales los individuos derivan su identidad" (1996, p. 21).

Las subjetividades han de ser pensadas no solo desde el ángulo de las sujeciones y restricciones a la libertad sino también desde el de las potencialidades, al tiempo que una pedagogía de la memoria buscará potenciar de la mejor manera los recuerdos y olvidos individuales y sociales, a favor de subjetividades reflexivas y críticas que se apropien de manera creativa del bagaje social acumulado y sepan tomar distancia de aquello que no consideren pertinente. Lo importante del análisis y comprensión de lo que somos en la actualidad cobra relevancia por el hecho de que nos impele a pensar por qué hemos llegado a ser lo que somos, no solo como individuos sino también como sociedades, $y$, en esta misma medida, podemos preguntar cómo dejar de ser aquello que los poderes estatuidos nos han impuesto como lo que deberíamos ser (Foucault, 1997).
Es preciso pensar a lo social y al sujeto como partes del mismo entramado cuando se trata de imaginar lo que denominamos otros mundos posibles. En este sentido, cuando se piensa en nuevos órdenes sociales es necesario propiciar, en su seno, la configuración de sujetos de esta misma naturaleza. Según Castoriadis:

Nos encontramos aquí de una sola vez, portados por dos ejes. Por una parte, la creación históricosocial como tal, con la aparición de una forma de sociedad capaz de cuestionarse a sí misma, $y$, por lo tanto, la creación de una nueva forma de ser en el nivel de lo histórico-social. Esto se amoneda por la aparición de las instituciones -incluso si no es más que un primer inicio del proyecto de autonomía-que se llaman democráticas: un espacio público, una memoria pública accesible a todos, la posibilidad del diálogo abierto, pero también, y sobre todo, la creación de instituciones entre las instituciones sociales, que apuntan a producir individuos capaces de reproducir esta forma de sociedad, a saber, individuos libres, cuestionantes, y no individuos sujetos (en el sentido monárquico del término) (2002, p. 273). 
Trazos de una pedagogía de la memoria y de la alteridad ${ }^{17}$

Concebir la vida humana como biografía es tratar de pensarla como relato, lo que significa que el sujeto humano es, como pensaba Proust, un novelista y un lector de sí mismo.

Bárcena, F. y Joan C. Melich

Pensar en una pedagogía de la memoria y de la alteridad significa reflexionar sobre los siguientes interrogantes que interpelan nuestra humanidad: ¿Cómo se concibe al Otro en escenarios de violencia política? ¿Qué sucede cuando deshumanizo al Otro convirtiéndolo en mi enemigo o en objeto de desprecio de mi accionar, en alguien que es necesario exterminar, pues se convierte en un obstáculo o simplemente no es útil a un sistema de poder que da mayor sentido a la acumulación de riquezas que a la propia vida? ¿Qué pasa con el Otro cuando no existe un yo que se responsabilice de sus acciones, cuando existen personas sin rostro que ejecutan acciones en contravía de la dignidad humana?

En el marco de estas preguntas, para una sociedad como la nuestra que convive con la violencia política, es necesario identificar situaciones en las que el rostro del Otro ${ }^{18}$ y todo lo que de allí se deriva se asumen en permanentes tensiones. La primera de ellas es la ausencia del rostro de quien debe hacerse responsable, y la segunda es la ausencia del rostro de quien me victimiza o a quien victimizo ${ }^{19}$. Situaciones que se complejizan ante la existencia de instituciones inmunizadas, amnésicas y anestesiadas que se niegan a reconocer que la tragedia, lo horrible,

17 Este apartado ha sido construido colectivamente con los estudiantes Pablo Vargas y Clara Castro, inscrito como una de las producciones del proyecto y del seminario temático Pedagogía de la alteridad en contextos de violencia política. Maestría en Educación. 2010. UPN. Bogotá.

18 En la pregunta por el rostro del Otro, nos acompaña Levinas (1991), para quien la subjetividad es entendida como responsabilidad inderrogable, responsabilidad convocada por la voz de lo Infinito, siempre despertada y audible desde lo humano próximo.

19 Al respecto, plantea Levinas (1991) que el rostro del Otro me indica su presencia, me posibilita hacerme responsable de él. En ciertas situaciones, la alteridad se rompe cuando el Otro a quien quiero acoger desaparece en su cuerpo y en su rostro, es violentar las relaciones humanas mismas. Para dar cuenta de esta ausencia del Otro, presentamos un fragmento del testimonio de una mujer que perdió a un familiar en circunstancias de violencia política: "Hoy ha sido difícil. Fui a conseguir el certificado de que mi esposo está desaparecido. No me pueden dar el certificado de que está muerto porque no hay cuerpo. Dicen que lo podrán hacer en dos años y entonces seré una viuda. Me ha hecho sentir muy mal. Yo sé que él ya no está, claro, pero hasta ahora no se sentía del todo real". "Nunca los perdonaré. Es más, enseñaré a mis hijos a no perdonar. ¿Cómo podría, cuando ni siquiera puedo decirle a mis hijos acá es en donde descansa (o este el rostro de) su padre?" (http://www.acnur.org/t3/index.php?id=164) 
lo monstruoso y lo extraño también forman parte de la vida humana, sabiendo que lo inhumano genera e instaura condiciones y actuaciones despreciativas entre los sujetos (Bárcena, 2005). Asimismo la prevalencia de expresiones de desconfianza en la constitución de lazos sociales y la relativización de límites en los procesos de regulación ética.

Estamos entonces ante un país en el que la alteridad se tramita como un acto de desprecio y de impudencia. Al respecto expresa Gallo (2008):

Lo predominante en cada ser humano ante la cercanía del otro, será la rivalidad, los celos, la hostilidad, la indiferencia, el desprecio abierto o velado, la explotación, la exclusión o la segregación y, en los casos más graves, la degradación directa y desvergonzada, tal como sucede cuando hay conflicto armado. Estas formas de desprecio al otro, entre las cuales debe contarse el desplazamiento forzado y el destierro, son las que llevan a su máxima expresión los agentes de la guerra. Las víctimas del conflicto armado son objeto de una degradación que avanza hasta convertirlos, como afirmara Kant, "únicamente en medio para mis fines (p.3).
Situaciones que están marcando un cambio en los sentidos de la vida individual y colectiva, imponiendo la degradación del sujeto, la desposesión de su dignidad y la inscripción en los excesos, en las rupturas de los límites, en la desresponsabilidad de sí mismo y con el otro. Es por ello que desde la revitalización de la memoria y de la alteridad se hace necesaria la emergencia de expresiones de indignación y de acciones de restitución de los derechos, para que la historia injusta no se convierta en rabia paralizadora o violenta, sino en potencialidad y vocación transformadora.

En este escenario una pedagogía de la memoria y de la alteridad se sustentan en una perspectiva de la pedagogía crítica (Giroux, 2003), la cual es considerada como una filosofía de la praxis, a partir de la cual se interroga acerca de la problematización del poder, la historia, la cultura y el contexto, con el interés de señalar como estos son constitutivos de la subjetividad y de los procesos de socialización éticapolítica. Se asume también como un campo de resignificación en torno a los modos de constitución y socialización de los sujetos (memoria individual y memoria colectiva) y como agenciamiento de los procesos de formación ética-política en diálogo con las configuraciones del vínculo social.

Para nuestra propuesta pedagógica la relación con el otro, como lo sugieren Bárcena y Mélich (2000), 
no es una relación contractual o negociada, no es una relación de dominación ni de poder, sino de acogimiento. Es una relación ética basada en una nueva idea de responsabilidad. Es una pedagogía que reconoce que la hospitalidad precede a la propiedad, porque quien pretende acoger a otro ha sido antes acogido por la morada que él mismo habita y que cree poseer como algo suyo.

Es por ello que una pedagogía de la memoria significa abordarla desde múltiples relatos, proyectos y prácticas; por eso crea comunidades de memoria en donde se recuerda, se interpreta, se resignifica, se crean lazos de identidad, pertenencia y compromiso y se aprende a argumentar, a negociar, a generar sentidos compartidos. De ahí que su articulación con una pedagogía de la alteridad hace posible que los recuerdos que están en unas cuantas personas se colectivicen, se enriquezcan, se amplíen, se conviertan en memoria colectiva y se mantengan. La memoria es constitutiva de la condición humana, por ello se inscribe en posiciones enunciativas y en formas de habitar la existencia social.

Una pedagogía de la memoria y de la alteridad es una práctica democrática sensible al contexto y políticamente transformadora. El modo en que se experimenta y designa el sentido de la realidad constituye el referente primario para la construcción de prácticas que son potencialmente políticas y éticas, dados sus fines colocados en una acción responsable y respondiente del sujeto. De acuerdo con Bárcena, "a través de ella respondemos no sólo ante las propias intenciones o convicciones, sino ante las consecuencias de los actos, cargando con la responsabilidad de las mismas de antemano" (2005, p. 174).

Abordar la alteridad significa asumirla como una pedagogía del nos-otros, constructora de vínculos, este "no es primariamente ni contractual ni virtual, es reconocimiento mutuo de dignidades, en el cuidado del otro en su singularidad material, síquica, social y corporal" (Cullen, 2004, p. 117). Por solidaridad se pretende significar una pulsión de alteridad, un deseo metafísico (Lévinas, 2001) por el otro que se encuentra en la exterioridad del sistema donde reina la tolerancia y la intolerancia. Es, acogiendo el planteamiento de Dusse ${ }^{20}$, un hacerse-cargo del otro reflexivamente. 
Recogiendo estos planteamientos, estas pedagogías se instituyen en un proyecto ético-político en el que la acción pedagógica se propone como relación con el otro (alteridad) basada en la responsabilidad y en recogimiento del otro (hospitalidad). Categorías necesarias a desplegar en el acto pedagógico como contenido y referente de un proyecto formativo. La pedagogía para estos tiempos requiere producir la comprensión del otro desde prácticas reflexivas, hermenéuticas y de compromiso. En ese sentido, la pedagogía introduce el cuidado formativo del otro, es una pedagogía de la solicitud.

Encontramos entonces que si la relación entre ética y política está dada en materia de responsabilidad y pluralidad, entre acogida y vínculo frente a un Otro diferente, con respecto a un Otro que dota de sentido mi humanidad, ¿cómo construir principios ético-políticos en medio de relaciones de exclusión, marginación, negación y eliminación de la diferencia? Ortega, nos propone tres elementos que a nuestro juicio son claves en la construcción de caminos posibles hacia horizontes ético-políticos y por lo tanto vale la pena profundizar en ellos develando algunos de los desafíos desde la propuesta de una pedagogía de la memoria y de la alteridad. Estos elementos son: la solidaridad compasiva, el análisis crítico de la realidad y el responder y responsabilizarse con el otro. Al respecto señala:
Una pedagogía entendida como acto y actitud ética de acogida, que nos libera de un intelectualismo paralizante y nos obliga a hacer recaer la actuación educativa no tanto en ideas, creencias y conocimientos cuanto en la persona concreta del educando. En Lévinas hay una clara voluntad de sustituir la autorreflexión, la autoconciencia, fundamento de la ética individualista, por la relación con el otro como propuesta de una moral alternativa; un distanciamiento de la ética como amor propio y el anclaje en otra que construye su significado a partir de la relación con el otro. Esta nueva concepción de la ética tiene unas inevitables consecuencias en la educación (...) Esto se traduce en el desarrollo de la empatía, del diálogo, de la capacidad de escucha y atención al otro (estar pendiente del otro), de la solidaridad compasiva como condición primera de una relación ética, pero también de la capacidad de analizar críticamente la realidad del propio entorno desde parámetros 
de justicia y equidad, de asumir al educando en toda su realidad, porque al ser humano no se le puede entender si no es en su entorno, en la red de relaciones que establece con los demás. Ser persona responsable es poder responder del otro. Y ello no es posible sin la apertura al otro como disposición radical ${ }^{21}$.

La solidaridad compasiva o la relación ética con el rostro de ese Otro que sufre, se ubica como respuesta, emocionalidad y acogida. Así lo referencian Bárcena y Mélich: "Me hago cargo del otro cuando lo acojo en mí, cuando le presto atención, cuando doy relevancia suficiente al otro, a su historia, a su pasado. Así la hospitalidad no se orienta solo al futuro, sino que tiene que ver con el pasado que los otros han sufrido" (2000, p. 146).

Aquí es importante recuperar la importancia que estos autores le brindan al pasado como posibilidad de comprensión ante lo que le ha sucedido a ese Otro, como fuente temporal, interpretativa y reflexiva, que hace uso de la narración como recurso para contar la historia.

De esta manera, es la solidaridad la que comienza a romper con posturas indiferentes y justificatorias de los hechos violentos y la que desde la interpretación del pasado, posibilita la comprensión de nuestro presente, develando no solo las condiciones estructurales de la violencia que padecemos, sino además los impactos que dicha violencia ha dejado en las víctimas directas y en el conjunto de nuestra sociedad. De esta comprensión se desprenden transformaciones en nuestra relación con el Otro, que con su presencia nos interpela y nos invita a construir una relación ético-política basada en la memoria, la justicia y la responsabilidad. De allí que para autores como Ricoeur exista una relación expresa entre el deber de la memoria y la idea de justicia, en la medida en que

Entre todas las virtudes, la justicia es la que, por excelencia y por constitución, se dirige hacia el otro. Se puede decir incluso que la justicia constituye el componente de alteridad de todas las virtudes que ella sustrae al cortocircuito entre sí mismo y sí mismo. El deber de la memoria

21 Ortega, P. La educación moral como pedagogía de la alteridad. En: http://www.mercaba. org/ARTICULOS/E/la_educacion_moral_como_pedagogi.htm. Consultado en septiembre 24 de 2011 
es el deber de hacer justicia, mediante el recuerdo, a otro distinto de sí (2002, p. 120)

Queda claro entonces que la comprensión del pasado enfatiza en la relación existente entre pedagogía de la memoria y la alteridad, develando las injusticias cometidas y posibilitando la realización de lecturas críticas de nuestra realidad que permitan la constitución de subjetividades ético-políticas inscritas en la historia y en el reconocimiento de lo subalternizado y excluido. De esta manera, una propuesta de pedagogía de la memoria y de la alteridad posibilita la constitución de subjetividades a partir del reconocimiento del Otro diferente, de sus particularidades culturales, creencias, historias de vida. Relación que está marcada por el respeto hacia ese Otro, con quien se edifica una relación intersubjetiva asimétrica, en donde me hago responsable del Otro, sin esperar nada a cambio, me hago responsable incluso antes de elegirlo.

En suma, una pedagogía de la memoria y de la alteridad situada en condiciones y expresiones de violencia política le urge trabajar en procesos de formación éticopolítica que posibilite la reafirmación de la dignidad de las víctimas, restituir derechos, agenciar dinámicas de constitución de vínculos, reelaborar las consecuencias de los actos de crueldad y terror y sus síntomas y efectos en las subjetividades de jóvenes y maestros que luchan por sobrevivir en medio de la desconfianza, el desprecio, la indolencia, la desvergüenza, el miedo y la venganza. Como sugieren Bárcena y Mélich: "No puede haber futuro sin memoria del pasado. Un futuro sin memoria es un futuro injusto, inmoral" (2000, p. 31).

Finalmente, la explicitación de estas tematizaciones las ponemos a disposición del acto pedagógico como contenido y referente de las narrativas formativas. De ahí que la pedagogía para estos tiempos requiere producir la comprensión del otro desde experiencias reflexivas, hermenéuticas y de compromiso; en ese sentido la pedagogía introduce el cuidado formativo del otro, es una pedagogía de la solicitud.

Es nuestro interés situar las narrativas sobre pedagogías de la memoria y de la alteridad que se agencian en múltiples espacios escolares y no escolares, con el fin de reconocer las construcciones de alteridad en los procesos de formación ética-política de maestros y que, a su vez, ellos dinamizan en sus instituciones. Será de gran interés, posteriormente, identificar las prácticas instituyentes desde donde se trabajan estas narrativas, referidas a los libretos sobre la convivencia, la democracia, las normas, dispositivos de regulación, emprendimientos de inclusión, procesos de vínculo pedagógico y soportes de la memoria. 


\section{Referencias}

Arfuch L. (2008). El espacio teórico de la narrativa: un desafío ético y político. En: Utopía y praxis latinoamericana. Año 13, No. 42 (julio-septiembre), p. 131-140.

Bárcena, F; Mélich J-C. (2000). La educación como acontecimiento ético. Barcelona: Paidós.

Bárcena, F. (2005). La experiencia reflexiva en educación. Barcelona: Paidós.

Blair, E. (2002). Memoria y narrativa: La puesta del dolor en la esfera pública. Estudios políticos No 21, Medellín, Junio-Diciembre. http://bibliotecavirtual.clacso.org.ar/ar/libros/colombia/iep/21/memoria\%20y\%20narrativa.pdf. p. 9- 28.

Cabrera, M. (2005-2006). Exceso y defecto de la memoria: violencia política, terror, visibilidad e invisibilidad. Oasis, No. 011, Universidad Externado de Colombia, Bogotá, Colombia, pp. 39-55.

Castillejo, A. (2000). Poética de lo otro. Antropología de la guerra, la soledad y el exilio interno en Colombia. Bogotá: Ministerio de Cultura, Icanh.

Castoriadis, C. (2002). Sujeto y verdad en el mundo histórico y social. México: Fondo de Cultura Económica.

Chartier, R. (1992). El mundo como representación. Historia cultural: entre prácticas y representaciones. Barcelona: Gedisa.

CINEP. (2008). Marco conceptual banco de datos derechos humanos y violencia política. Documento de trabajo. Bogotá.

CINEP. (2009). Informe especial. Primer Semestre de 2009: De los 'falsos positivos' a la intolerancia social y las amenazas colectivas. Bogotá.

Connerton, P. (1989). How Societies Remember. London: Cambridge University Press.

Cuesta J. (2008). La odisea de la memoria. Madrid: Alianza Editorial.

Cullen, C. (2004). Perfiles ético-políticos de la educación. Buenos Aires: Paidós.

Cullen, C. (2008). Entre desarrollo y educación; ética, ¿dónde habitas? Disponible en: http://www.oei.es/noticias

Cruz, M. (1996). Tiempo de subjetividad. Barcelona: Paidós.

Cruz, M. (2000). Tiempo de narratividad (el sujeto, entre la memoria y el proyecto). Quaderns de comunicació i cultura, № 25 , p. 23-40. 
Dussel, E. (1996). La ética de la liberación ante la ética del discurso. México: UNAM.

Dussel, E. (2009). Reconstrucción del concepto de tolerancia. (De la intolerancia a la solidaridad). Tomado de la página electrónica de la Asociación de Filosofía y Liberación. http://www.afyl.org/info.html http:// www.afyl.org/info.html

De la Garza, E. (2001). Subjetividad, cultura y estructura. Revista Iztapalapa No. 50. México: Universidad Autónoma Metropolitana Unidad Iztapalapa, p. 83-104.

Elías, N. (1997). El proceso de la civilización. Bogotá: Fondo de Cultura Económica.

Foucault, M. (1997). Historia de la sexualidad II. El uso de los placeres. México: Siglo XXI.

Galeano, E. (2007). Estrategias de investigación social cualitativa. Medellín: La Carreta Editores.

Gallo, H. (2008). Sin vergüenza: Amarás al prójimo. Conferencia evento académico destierro y reparación y la Nueva Escuela Lacaniana -NEL-. Medellín. http://www.destierroyreparacion.org/sites/default/files/ Amarasalprojimo-textoconversatorioHector.pdf

Garrier A. y Kagroix B. (eds.) (1997). Norbert Elias. La politique et I'histoire. Paris: La Découverte.

Giraldo, J. (2000). Memoria histórica y construcción de futuro. Texto escrito como parte de la introducción a la primera entrega del informe Colombia nunca más. Bogotá. Disponible en: www.javiergiraldo.org
Giroux, H. (2003). Pedagogía y política de la esperanza. Teoría, cultura y enseñanza. Buenos Aires: Amorrortu.

Giroux, H. (2008).Teoría y resistencia en educación. México: Siglo XXI.

Gómez, E. (2009). La impunidad, salvavidas para el terrorismo de Estado. Hechos y cifras de horror. Le Monde Diplomatique. Edición No. 33. Disponible en http://eldiplo.info/mostrar_articulo. php?id=76\&numero $=33$

Grupo de trabajo pro reparación integral. (2008). La dimensión política de la reparación integral. En: Voces de Memoria y Dignidad. Material Pedagógico sobre Reparación Integral. Bogotá.

Guidens, A. (2003). La constitución de la sociedad: bases para la teoría de la estructuración. Buenos Aires: Amorrortu.

Guzmán, F. (2008). Michel Foucault: El pensamiento de la contingencia. Revista Observaciones Filosóficas № 6. México: Universidad Michoacana, U.M.S.N.H., p. 1-14.

Halbwachs, M. (2008). La memoria colectiva. Zaragoza: Universidad de Zaragoza.

Huyssen, A. (2007). En busca del futuro perdido. Cultura y memoria en tiempos de globalización. Buenos Aires: Fondo de Cultura Económica. Jelin, E. (2002). Los trabajos de la memoria. Buenos Aires: Siglo XXI.

Jelin, E. (2003). Los derechos humanos y la memoria de la violencia política y la represión: la construc- 
ción de un campo nuevo en las ciencias sociales. Buenos Aires: Instituto de Desarrollo Económico y Social.

Laverde, M.C., Daza G., Zuleta M. (ed.) (2004). Debates sobre el sujeto. Bogotá: Siglo del Hombre.

León E. y Zemelman H. (coords.) (1997). Subjetividad. Umbrales del pensamiento social. Barcelona: Anthropos.

Lévinas, E. (2001). Entre nosotros. Ensayos para pensar en otros. Valencia: Pre-textos.

Lévinas, E. (2002). Totalidad e infinito: Ensayo sobre la exterioridad. Salamanca: Sígueme.

León, E. (2009). Los rostros del otro. Reconocimiento, invención y borramiento de la alteridad. México: Anthropos, Centro Regional de Investigaciones Multidisciplinarias- CRIM.

Merleau-Ponty. (1975). Fenomenología de la percepción. Barcelona: Península.

Muñoz G. (2007). ¿ildentidades o subjetividades en construcción? Revista de Ciencias Humanas, No. 37, Tunja: UPTC, p. 6989.

Prada, M; Ruiz, A. (2007). Cinco fragmentos para un debate sobre la subjetividad política. Documento de trabajo. Bogotá: Universidad Pedagógica Nacional.

Pécaut, D. (2004). Memoria imposible, historia imposible, olvido imposible. Memorias en conflicto. Aspectos de la violencia política contemporáneas. Lima: IEP-IFEA.

Ortega, P. La educación moral como pedagogía de la alteridad. Fuente: www.revistadepedagogia.org/repn227.htm

Quintero, M; Ramírez, J. (2009). Narraciones, Memorias y Ciudadanía. Desplazamiento Forzado. Bogotá: Universidad Distrital.

Ricoeur, P. (2001). Del texto a la acción. Ensayos de Hermenéutica II. Argentina: FCE.

Ricoeur, P. (2002). La historia, la memoria, el olvido. México: Fondo de Cultura Económica.

Ricoeur, P. (2006).Caminos del reconocimiento. México: Fondo de Cultura Económica.

Reguillo, R. (1999-2000). Anclajes y mediaciones del sentido. Lo subjetivo y el orden del discurso: un debate cualitativo. Revista Universidad de Guadalajara. Número 17/Invierno 1999-2000. http://www.cge.udg.mx/revistaudg/rug17/4anclajes.html. Consultada en agosto 27 de 2011.

Rodríguez J. A. (2009). Asedio a las narrativas contemporáneas. Mapa de posibles investigaciones. Cuadernos de Literatura, Bogotá, Colombia, V.14, № 26, julio-diciembre, p. 14-51. 
Rose, N (2001). Inventing ourselves. United Kingdom: Cambridge University Press.

Rossi, P. (2003). El pasado, la memoria, el olvido. Buenos Aires: Nueva Visión.

Scott, J. (2001). Experiencia. La Ventana, No. 13, p. 42-73.

Taylor, S. J., Bogdan, R. (1992). Introducción a los métodos cualitativos de investigación. En la búsqueda de significados. Barcelona: Paidós.

Vanegas, G. (2002). La institución educativa en la actualidad: un análisis del papel de las tecnologías en los procesos de subjetivación. Tesis doctoral. Universidad de Barcelona.

Vélez, J. C. (2003). Violencia, memoria y literatura testimonial en Colombia. Entre las memorias literales y las memorias ejemplares. Estudios Políticos, No. 22. IEP, Instituto de Estudios Políticos, Universidad de Antioquia, Medellín, Colombia. 